\title{
A study of morphological variations of the human ear for its applications in personal identification
}

\author{
Kewal Krishan ${ }^{1 *}\left(\mathbb{D}\right.$, Tanuj Kanchan ${ }^{2}$ and Swati Thakur ${ }^{1}$
}

\begin{abstract}
Background: External human ear is considered to be a highly variable structure showing different morphological and individualistic features in different individuals and population groups. The uniqueness of the ear may be useful in establishing the identity of individuals by direct examination, during the examination of CCTV footage or analysis of the ear prints. Considering the forensic significance of the human ear and ear prints encountered at the scene of the crime, the present study is an attempt to evaluate various morphological characteristics of the ear in a north Indian population.
\end{abstract}

Methodology: The sample for the present study comprises of 90 males and 87 females aged between 18 and 30 years. All the study participants were from upper reaches of Himachal Pradesh in North India. The morphological characteristics such as overall shape of the ear, size and shape of the tragus, earlobe, shape of the helix, and forms of Darwin's tubercle were studied in the participants.

Results: The oval-shaped ear was present among $40 \%$ of the males and $44.8 \%$ of the females in the study sample. The other types of the ear such as oblique, rectangular, round, and triangular were also found in both sexes. Bilateral asymmetry was observed in the shape of the ear. The shape of the tragus also varied with respect to the left and right sides as well as sexes. The earlobe showed different characteristics in different individuals. In nearly half of the cases in both males and females, the earlobe was found to be attached to the face; in many cases, it was free and in some partially attached. The size and shape of the earlobe also showed variations with respect to sides as well as sexes. The Darwin's tubercle showed a variety of structures in both the left and right sides in both sexes.

Conclusion: The present study shows that the individualistic characteristics of the ear can provide very useful information for personal identification in forensic examinations. The shape of the ear and the important structures such as the tragus, helix, earlobe, and Darwin's tubercle show a variety of structures and individuality. The importance and variability of the human ear may encourage the researchers in conducting further studies and solving the forensic cases pertaining to the investigation of CCTV footage and in examination of dead in airplane crashes, intentional mutilation and dismemberment, explosions, or other mass disasters.

Keywords: Forensic science, Forensic anthropology, Personal identification, Human ear, Morphological variations and uniqueness, North India

\footnotetext{
*Correspondence: gargkk@yahoo.com; kewalkrishan@pu.ac.in

The paper was presented by Dr. Kewal Krishan in 67th Annual Scientific

Meeting of the American Academy of Forensic Sciences (AAFS) held at

Orlando, Florida, USA, from 16 to 21 February 2015.

'Department of Anthropology (UGC Centre of Advanced in Anthropology),

Panjab University, Chandigarh 160 014, India

Full list of author information is available at the end of the article
} 


\section{Background}

In the past, many morphological and metric features of the human body have been used for personal identification in forensic examinations. Fingerprints, footprints, facial characteristics and features, iris, gait, teeth, bite marks, gait pattern, lip prints, voice characteristics, and DNA fingerprinting from a variety of tissues of the human body have successfully been utilized in forensic situations as well as for identification of criminals. The human ear is another organ of the body which is unique to an individual. Like fingerprints and other characteristics of the human body, the ear retains certain individualistic characteristics which are unique due to variations in the anatomical structure of the external ear (Iannarelli 1989). In certain situations, where the dead body is recovered in dismembered or mutilated conditions, the shape, size, and individualistic features of his ears may be useful in identifying the deceased along with other identification characteristics of the human body. In the recent past, it has also been shown that like the ear, the prints left by the human ear are also individualistic to an individual (Krishan and Kanchan 2016; Meijerman 2006). The earprints can be left by the criminals/burglars while listening at the doors or windows of the target house. In the present scenario when the crimes are recorded by CCTV cameras, an expert may be asked to identify the individual/suspect on the basis of CCTV footage where the ear of the suspect is clearly visible.

Many studies have been conducted worldwide to show variations in human ears morphologically and morphometrically. Some recent studies (Rubio et al. 2017; Cameriere et al. 2011; Purkait 2016; Verma et al. 2016; Vanezis et al. 1996) have shown that every part of the external ear is morphologically unique and shows reasonable variations in individuals and population groups. These studies have described different types and shapes of the ear, various forms of the helix and tragus, types of Darwin's tubercles, shape size, and forms of the earlobes. The occurrence and frequencies with respect to these characteristics have been calculated, and population-based characteristics have been compiled to link these characteristics with a community. Some studies have metrically observed the structure of the ear (Ahmed and Omer 2015; Dinkar and Sambyal 2012; Sforza et al. 2009; Purkait and Singh 2007; Gibelli et al. 2012; Purkait and Singh 2008) such as linear distances, ratios, growth changes in the ear, and bilateral asymmetry of the ear and tried to formulate the population and community characteristics for anthropological and forensic use. Most of these studies have shown that the ear dimensions are metrically variable in individuals and populations, the ear parameters are significantly larger in males than females, and ears show bilateral asymmetry. Some studies have shown how the shape and size of the ear can be predicted for facial reconstruction in forensic examinations (Guyomarc'h and Stephan 2012; Swift and Rutty 2003).

The study will impact the forensic science community by presenting new information on variability and uniqueness of the human ear in an Indian population and usefulness of the human ear in personal identification. Therefore, looking at the value of the human ear in forensic identification, the objective of the present investigation was to study the morphological characteristics of the human ear in a north Indian population. The study presents new information on variability and uniqueness of the human ear in an Indian population and usefulness of the human ear in personal identification in both sexes.

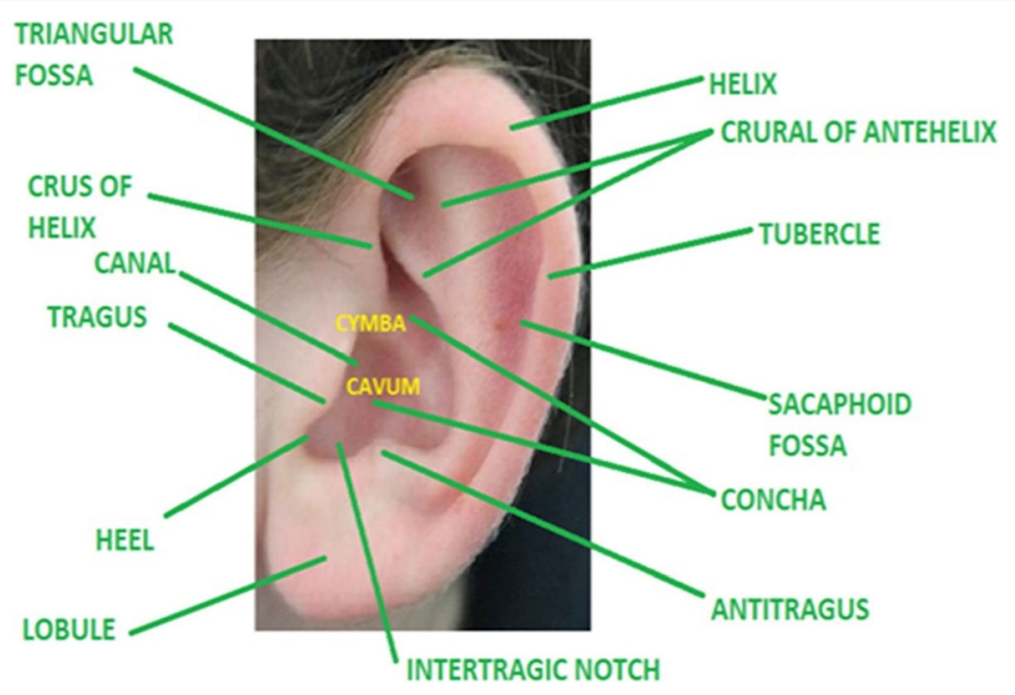

Fig. 1 A photograph showing the morphology and different parts of the ear 


\section{Materials and methods Subjects/participants}

The study was conducted in the selected areas of Kalpa and Reckong Peo in Kinnaur District of Himachal Pradesh State in North India. The data were collected on a sample of 177 North Indian young adults comprising 90 males and 87 females ranging in age from 18 to 30 years. The consent of the subjects was taken before initiating the data collection. The purpose and the meaning of the research were explained to each subject. The subjects with normal ears were included in the study; those with apparent deformity were excluded.

\section{Methodology}

Morphological characteristics of the study were evaluated in order to develop standards for the unique morphology of the ear in the population. The ears of the subjects were photographed, and some peculiar characteristics were noted in the studied population. The photographs of the ears were taken with the help of Sony Cyber-shot DSC-H55 camera at the same distance in all the subjects.

\section{Morphological characteristics of the ear}

The human ear can be considered as unique due its exclusive morphological structure and the organization of its various parts (Fig. 1). Overall shape of the ear; size and shape of the tragus; presence, thickness, and attachment of the earlobe; shape of the helix; forms of Darwin's tubercle; rare and special characteristics of the ear; hypertrichosis; etc. were studied in both left and right ears. Sex differences and bilateral asymmetry were also evaluated in these non-metric characteristics of the ear. The following anthroposcopic/somatoscopic characteristics/features were observed in the ears of the subjects followed by a study conducted by Singh and
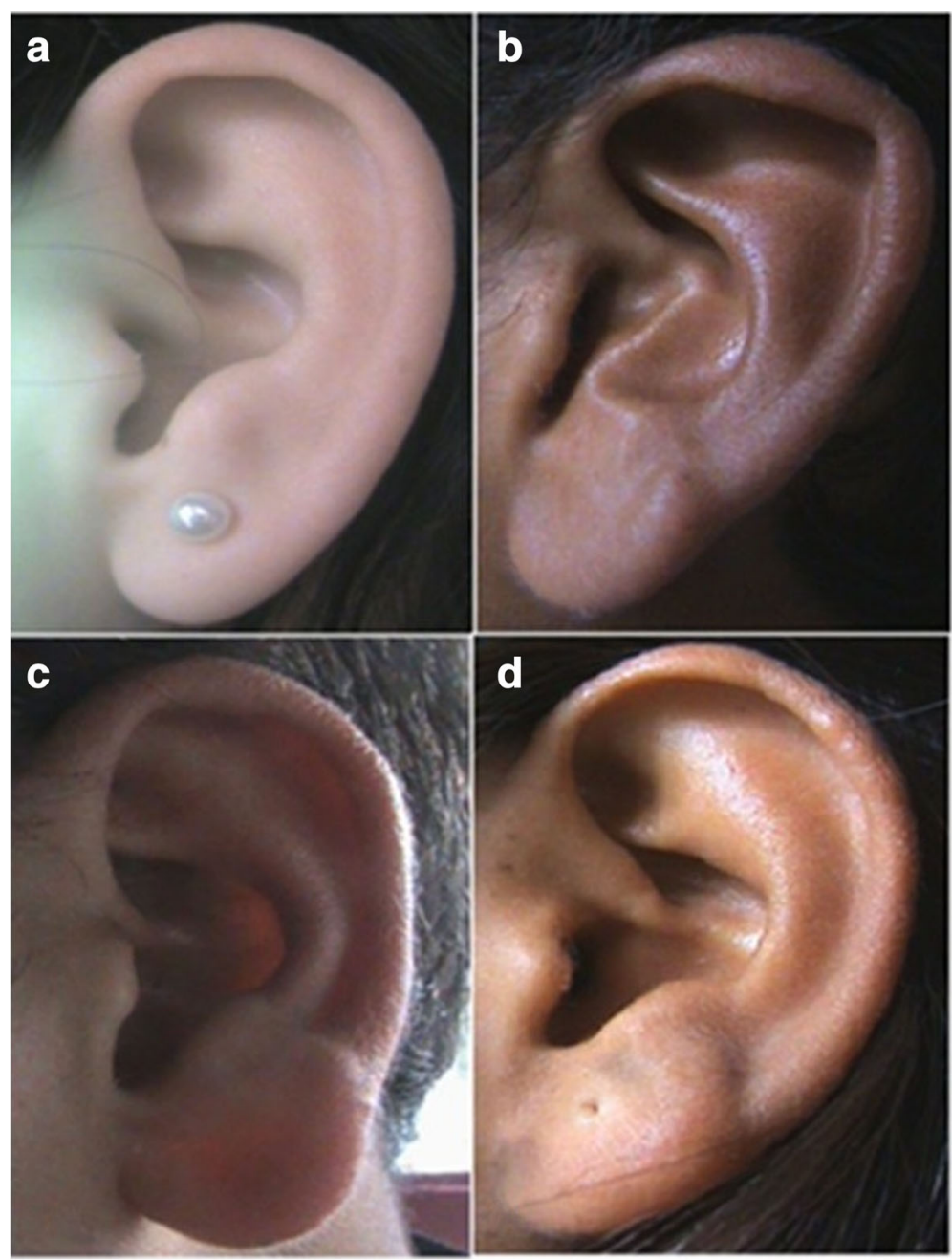

Fig. 2 Photographs showing the shape of the ear. a Oval. b Triangular. c Rectangular. d Round 


\section{Purkait (2009).}

Shape of the ear: Oval, oblique, rectangular, round and triangular (Fig. 2)

Shape of the helix: Concave marginal, normally rolled, flat and wise covering scapha (Fig. 3)

Shape of the earlobe: Arched, tongue, square and triangular (Fig. 4)

Attachment of the earlobe: Attached, free, partially attached to the skin (Fig. 5)

Thickness of the earlobe: Medium, thick and thin (Fig. 6)

Shape of the tragus: Double knob, single knob and round (Fig. 7)

Darwin's tubercle: Absent, enlargement, nodosity and projection (Fig. 8)

The frequency distribution of these traits was evaluated separately in males and females in both the left and right ears, and simple frequency tables were made for interpretation of the results.

\section{Results}

The results of the present study show that every ear is unique in shape and size and with respect to various other morphological features. The uniqueness/ individuality of the ear can be judged from the variable structure of the ear in every individual.

Table 1 shows the frequency of the overall shape of the left and right ears in the both sexes. Oval shape (Fig. 2) of the ear was common ( $40 \%$ males and $44.8 \%$ females for the left ear; $40.2 \%$ males and $46 \%$ females for the right ear) among the overall sample of the study in
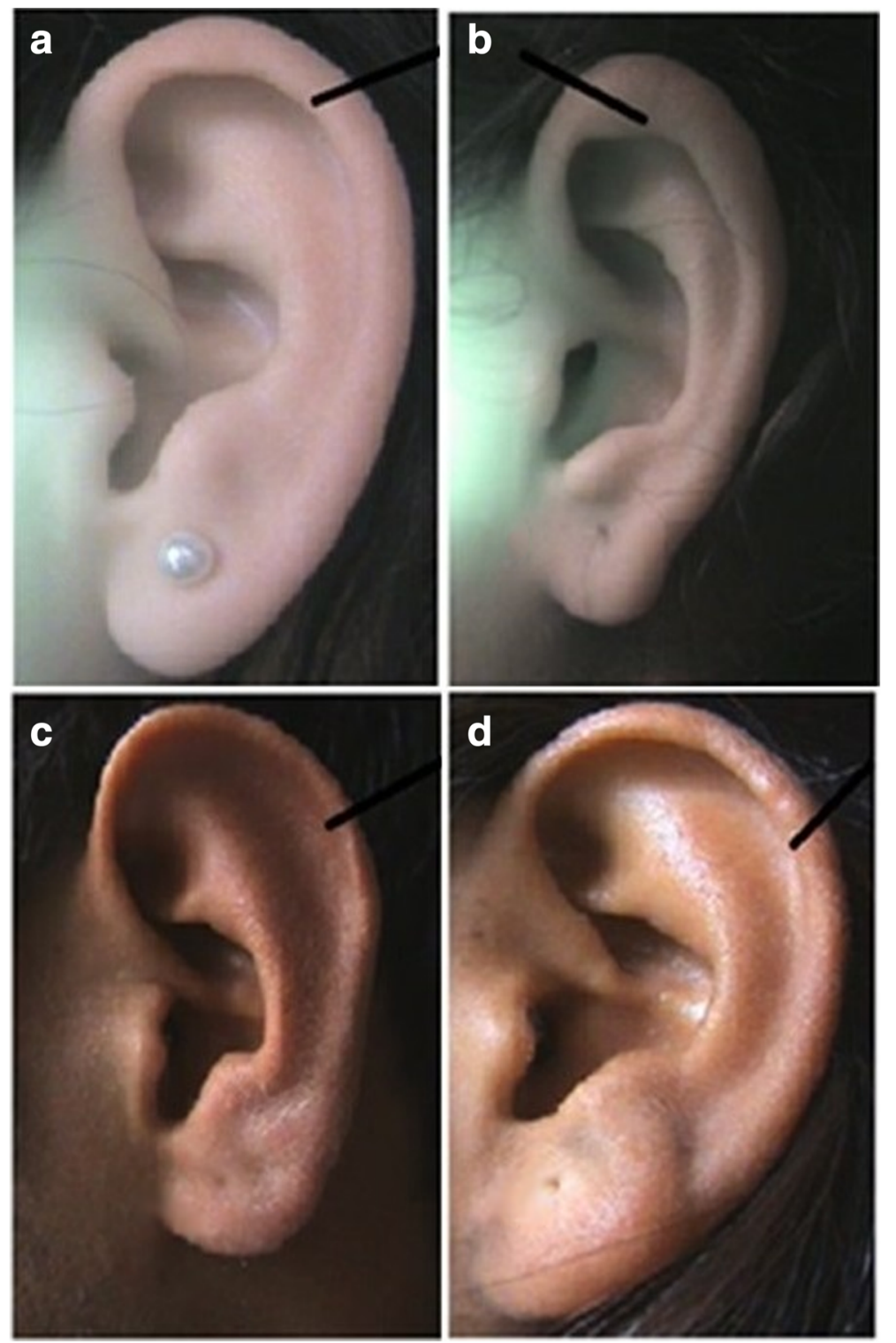

Fig. 3 Photographs showing the different forms of the helix. a Normally rolled. b Wide covering scapha. c Flat. d Concave marginal 

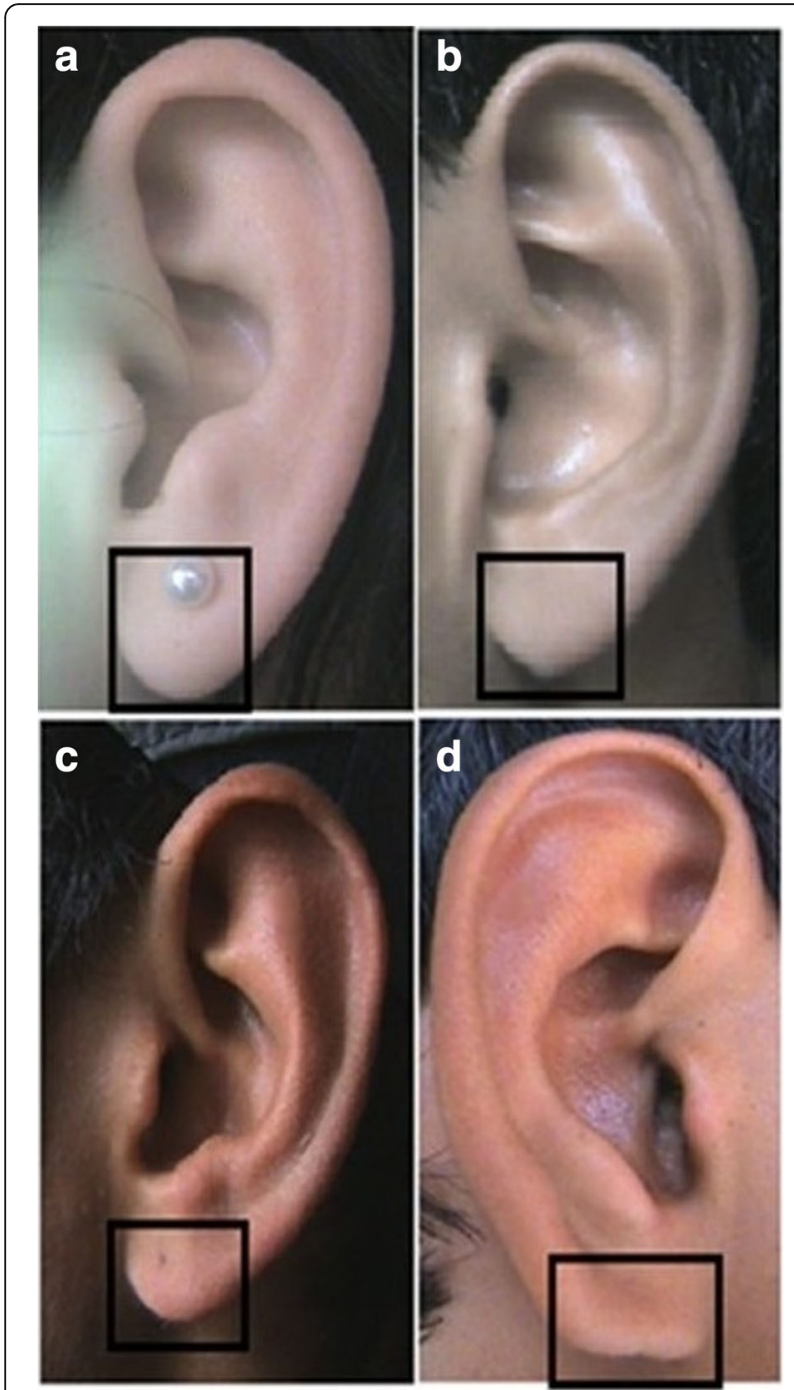

Fig. 4 Photographs showing the different shapes of the earlobe. a Tongue. b Triangular. c Arched. d Square

both sexes. The rectangular (8.9\% males $9.2 \%$ females for the left ear; $2.2 \%$ males and $8 \%$ females for the right ear) and triangular types $(8.9 \%$ males and 12.6 females for the left ear; $6.7 \%$ males and $11.5 \%$ females for the right ear) of the ears were the rare variants reported in the study. The other types of the ear such as the oblique and round were also found in both sexes. Slight sex differences were observed as regards the overall shape of the ears in the subjects. Bilateral asymmetry exists as regards the shape of the ear, however, not significant.

Table 2 details the frequency distribution of the shape of the helix (Fig. 3) among the subjects. The shape of the helix is highly variable in the individuals showing certain characteristics such as normally rolled helix, concave, flat, and wide covering scapha helix. Normally rolled helix was common $(51.1 \%$ males and $48.3 \%$ females for the left ear; $50 \%$ males and $44.8 \%$ females for the right ear) among both sexes in the studied population. The other types of the helix such as concave, flat, and wide covering scapha helix were present among rest of the subjects.

Table 3 shows the frequency distribution of the shape of the left and right earlobe (Fig. 4) among the studied sample. The shape of the earlobe may be of various kinds such as arched, tongue shaped, square, and triangular. Arched earlobe was found to be common (67.8\% males and $67.8 \%$ females for the left ear; $74.4 \%$ males and $72.4 \%$ females for the right ear) among both sexes in the studied population. The square type $3.3 \%$ males and 5.5\% females for the left ear; $4.4 \%$ males and $6.9 \%$ females for the right ear) and triangular types $(8.9 \%$ males and $10.3 \%$ females for the left ear; $5.6 \%$ males and $5.5 \%$ females for the right ear) of the earlobes were the rare variants reported in the study.

Table 4 indicates the frequency distribution of the attachment of the left and right earlobes (Fig. 5) that whether the earlobes are attached to the skin of the face, free (not attached to the skin of the face but hanging freely), and partially attached. The attached earlobe was common $(50.0 \%$ males and $56.3 \%$ females for the left ear; $53.3 \%$ males and $58.6 \%$ females for the right ear) among both sexes in the studied population. Partially attached earlobe was rare among the males and females on the left side; however, the free earlobe was found to be rare among the both sexes on the right side.

Table 5 indicates the frequency distribution of the thickness of the left and right earlobes (Fig. 6). The thickness of the earlobe is an important character which may be considered an individualistic feature of the person. The medium thickness of the earlobe was common $(64.4 \%$ males and $67.8 \%$ females for the left ear; $66.7 \%$ males and $67.8 \%$ females for the right ear) among the subjects in both sexes. The thick-type earlobes $(25.6 \%$ males and $16.1 \%$ females for the left ear; $23.3 \%$ males and $16.1 \%$ females for the right ear) and thin-type earlobes (10\% males and $16.1 \%$ females for the left and right ears) were also reported in the study.

Table 6 shows the frequency distribution of the shape of the tragus (Fig. 7) among both sexes in the studied subjects. Single knob tragus was found to be common (66.3\% males and $95.3 \%$ females for the left ear; $72.2 \%$ males and $94.3 \%$ females for the right ear) among both sexes in the studied population. The results indicate that the significant sex differences exist as far as the single knob tragus is concerned with predominance in females. The frequency of the double knob tragus was very low, $2.3 \%$ and $3.4 \%$ in the left and right ears of females, respectively; however, the trait is totally absent in males. Long-type tragus was absent in females; however, the trait was found among $4.4 \%$ and $5.6 \%$ of males on the left and right sides, respectively. Round-type tragus was 


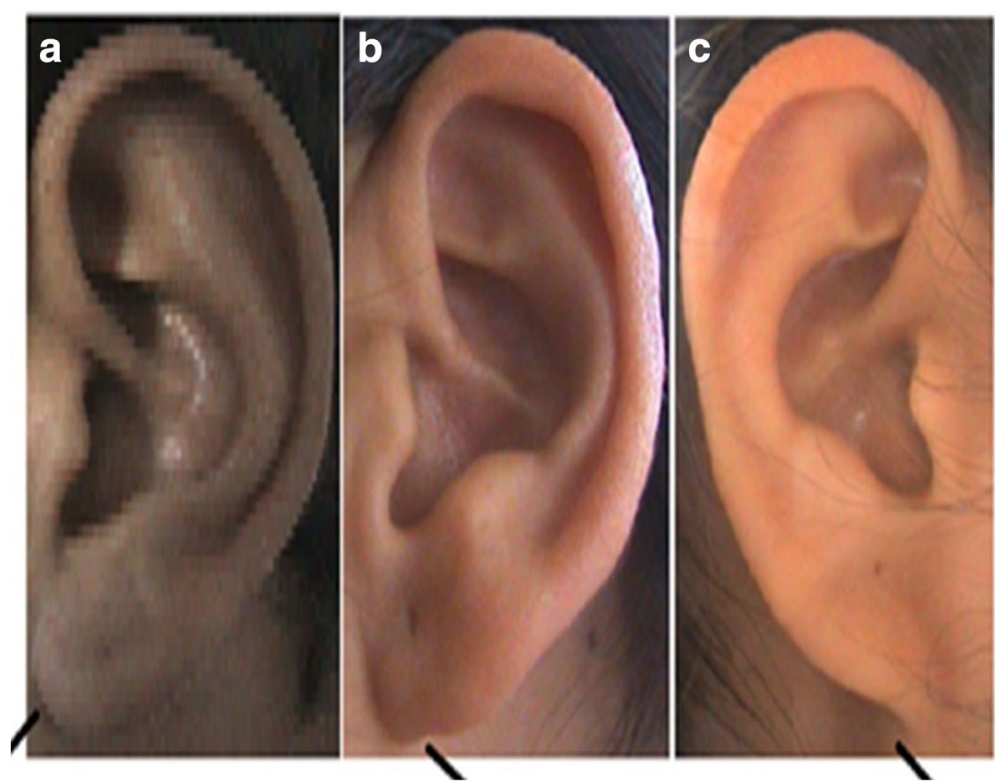

Fig. 5 Photographs showing the different forms of the earlobe attachment. a Free. b Partially attached. c Attached

observed in $22.2 \%$ and $2.3 \%$ on the left and right sides, respectively, in both sexes. The shape of the tragus also varies with respect to the left and right sides as well as sexes.

Table 7 shows the frequency distribution of the various shapes of the Darwin tubercles present on the left and right ears of the subjects. Darwin's tubercle refers to a congenital prominence usually found on the posterior part of the helix of the ear (Loh and Cohen 2016). In the present study, it shows a variety of structures in both the left and right sides in both sexes. The trait is usually found on the posterior aspect of the helix; however, in some cases, it was also found on the superior aspect in the present study (Fig. 8). Nodosity-type Darwin's tubercle was found to be common $(53.8 \%$ males and $46 \%$ females for the left ear;
$67.8 \%$ males and $47.1 \%$ females for the right ear) among both sexes. The study also shows that the nodosity-type Darwin's tubercle was more often found on the males' ears than the females' ears. Enlargement and projection form of the Darwin's tubercle was among the rest of the subject, and in few subjects, the Darwin tubercle was totally absent.

\section{Discussion}

The results of the study indicate that the oval-shaped ear was present among about $40 \%$ of the males and $44.8 \%$ of the females in the study sample. The other types of ear such as oblique, rectangular, round, and triangular were also found in both the sexes. Bilateral asymmetry exists as regards the shape of the ear. The size and shape of the tragus also vary with respect to the
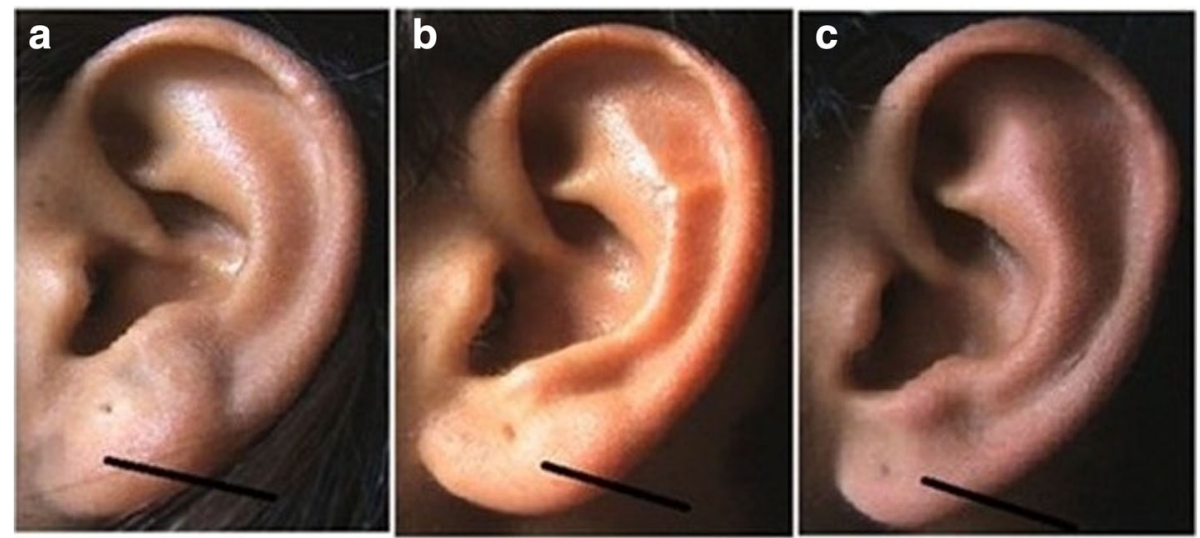

Fig. 6 Photographs showing the thickness of the earlobe. a Thick. b Medium. c Thin 

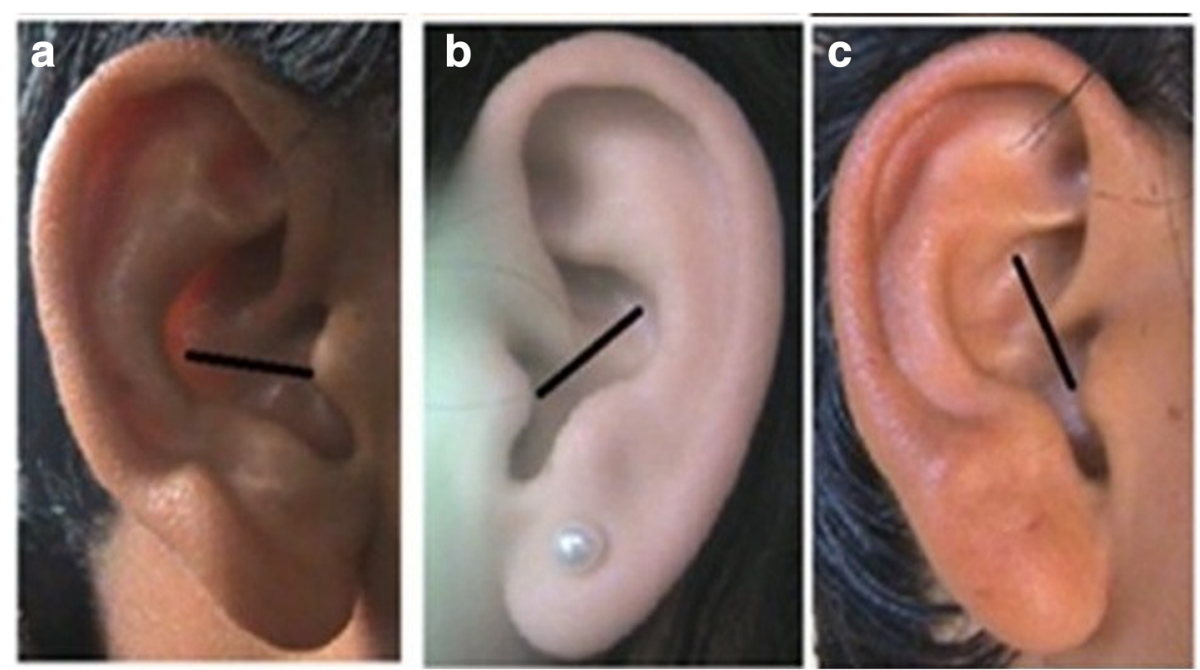

Fig. 7 Photographs showing the different shapes of the ear tragus. a Knob. b Round. c Long
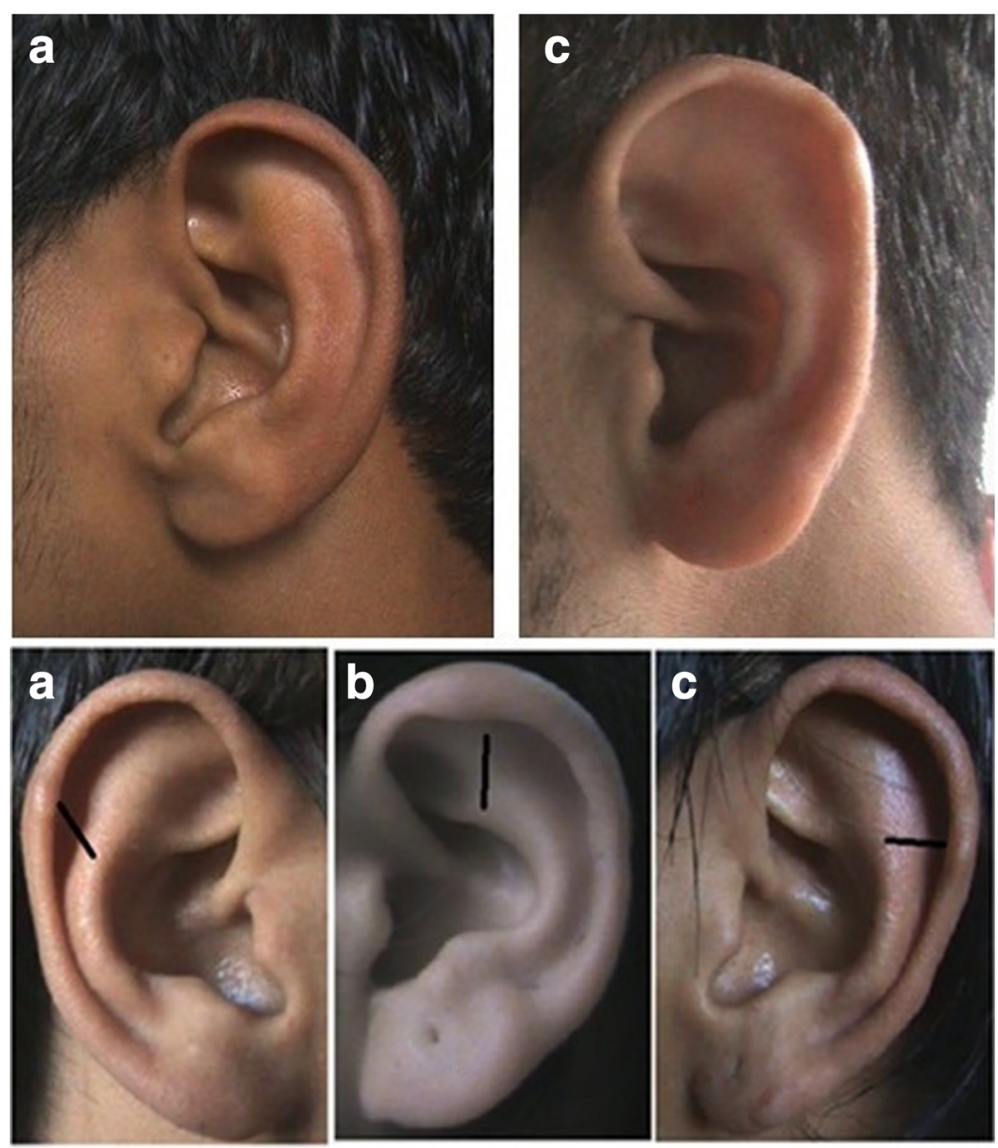

Fig. 8 Photographs showing the different forms of Darwin's tubercles. a Nodosity. b Enlargement. c Projection 
Table 1 Shape of the ear in males $(N=90)$ and females $(N=87)$ bilaterally

\begin{tabular}{|c|c|c|c|c|}
\hline \multirow{2}{*}{$\begin{array}{l}\text { Shape of } \\
\text { the ear }\end{array}$} & \multicolumn{2}{|l|}{ Male } & \multicolumn{2}{|l|}{ Female } \\
\hline & Right $(N, \%)$ & Left $(N, \%)$ & Right $(N, \%)$ & Left $(N, \%)$ \\
\hline Oval & $38,42.2 \%$ & $36,40.0 \%$ & $40,46.0 \%$ & $39,44.8 \%$ \\
\hline Oblique & $26,28.9 \%$ & $20,22.2 \%$ & $14,16.1 \%$ & $14,16.1 \%$ \\
\hline Rectangular & $2,2.2 \%$ & $8,8.9 \%$ & $7,8.0 \%$ & $8,9.2 \%$ \\
\hline Round & $18,20.0 \%$ & $18,20 \%$ & $16,18.4 \%$ & $15,17.2 \%$ \\
\hline Triangular & $6,6.7 \%$ & $8,8.9 \%$ & $10,11.5 \%$ & $11,12.7 \%$ \\
\hline Total & $90,100 \%$ & $90,100 \%$ & $87,100 \%$ & $87,100 \%$ \\
\hline
\end{tabular}

left and right sides as well as sexes. The earlobe showed different characteristics in different individuals. In nearly half of the cases in both males and females, the earlobe was found to be attached to the face; in many cases, it was free and some partially attached. Then, the size and shape of the earlobe also showed variations with respect to sides as well as sexes. The shape of the helix varies in individuals showing certain characteristics such as concave, rolled, flat, and wide covering scapha. The Darwin tubercle showed a variety of structures in both the left and right sides in both sexes. The extensive variability of the human ear may be attributed to the unique structure and characteristics of the ear. Previous studies (Cameriere et al. 2011; Guyomarc'h and Stephan 2012; Swift and Rutty 2003; Singh and Purkait 2009) have also shown that the variability of the external human ear in individuals is enough to enable individualization in forensic examinations and may help to solve the question whether a certain suspect could be identified as being offender. All these variable features and individualistic/ special characteristics of the ear may also help in individualization of the person in the CCTV footage of the crime scene (Hoogstrate et al. 2001).

A few studies are available in the literature (Rubio et al. 2017; Cameriere et al. 2011; Purkait 2016; Verma et al. 2016; Vanezis et al. 1996; Purkait and Singh 2008; Alexander et al. 2011; Kearney 2003) regarding the morphological characteristics of the ear which enhance the anthropological and forensic knowledge about the ear and its variability in different populations. The results of the morphological features of the ear in the
Table 3 Shape of the earlobe in males $(N=90)$ and females ( $N$ $=87$ ) bilaterally

\begin{tabular}{llllll}
\hline $\begin{array}{l}\text { Shape } \\
\text { of the } \\
\text { earlobe }\end{array}$ & Male & & & Female & \\
\cline { 6 - 6 } & Right $(N, \%)$ & Left $(N, \%)$ & & Right $(N, \%)$ & Left $(N, \%)$ \\
\hline Arched & $67,74.4 \%$ & $61,67.8 \%$ & & $63,72.4 \%$ & $59,67.8 \%$ \\
Tongue & $14,15.6 \%$ & $18,20 \%$ & & $13,15 \%$ & $14,16.1 \%$ \\
Square & $4,4.4 \%$ & $3,3.3 \%$ & & $6,6.9 \%$ & $5,5.7 \%$ \\
Triangular & $5,5.6 \%$ & $8,8.9 \%$ & & $5,5.7 \%$ & $9,10.4 \%$ \\
Total & $90,100 \%$ & $90,100 \%$ & & $87,100 \%$ & $87,100 \%$ \\
\hline
\end{tabular}

present study can be compared with a few similar studies conducted worldwide. According to Van der Lugt (2001), the Dutch males were found to possess $68.7 \%$ of oval-type ears and Americans have 65\% of oval-type ears in both sexes as observed by Iannarelli (1989) as compared to the subjects of the present study (nearly 40-46\%). However, generally, the oval-type ears are present more often than the any other types of ears in almost all these studies. The frequency of rectangular ears among the present study (2-9\%) was comparable to Dutch (9.1\%) but higher than in the Americans (3\%) as reported by the authors. The findings related to round-type ears in the present study males $(20 \%)$ and females $(17-18 \%)$ can be compared to the Dutch males (3\%) and the Americans (2\%). Chattopadhyay and Bhatia (2009) observed that Indian Brahmin males have a higher percentage of oblique type ears $(63.89 \%)$; on the other hand in the present study, the males have $22-29 \%$ of oblique-type ears. They further reported $27.19 \%$ of long and narrow ears, $46.49 \%$ medium ears, $26.31 \%$ short and broad ears, and $36.11 \%$ vertical type of ears in their study. Singh and Purkait in their study on the Central Indian population reported $47-52 \%$ oval-type ears, $26-30 \%$ rectangular type, $26-35 \%$ triangular-type ears, and $23-59 \%$ round type of ears; the trend is somewhat different and erratic from the findings reported in the present study.

As far as the variability of the structure of the helix is concerned, the helix shows a variety of structures. In the present study, nearly half of the subjects (44-51\%) possess normally rolled helix; however, Farkas (1978) found $76-79 \%$ of normally rolled helix in Americans,

Table 2 Shape of the ear helix in males $(N=90)$ and females $(N=87)$ bilaterally

\begin{tabular}{|c|c|c|c|c|}
\hline \multirow[t]{2}{*}{ Shape of the helix } & \multicolumn{2}{|l|}{ Male } & \multicolumn{2}{|l|}{ Female } \\
\hline & Right $(N, \%)$ & Left $(N, \%)$ & Right $(N, \%)$ & Left $(N, \%)$ \\
\hline Concave marginal & $35,38.9 \%$ & $37,41.1 \%$ & $25,28.7 \%$ & $24,47.6 \%$ \\
\hline Normally rolled & $45,50.0 \%$ & $46,51.1 \%$ & $39,44.8 \%$ & $42,48.3 \%$ \\
\hline Flat & $6,6.7 \%$ & $3,3.3 \%$ & $5,5.8 \%$ & $4,4.6 \%$ \\
\hline Wide covering scapha & $4,4.4 \%$ & $4,4.5 \%$ & $18,20.7 \%$ & $17,19.5 \%$ \\
\hline Total & $90,100 \%$ & $90,100 \%$ & $87,100 \%$ & $87,100 \%$ \\
\hline
\end{tabular}


Table 4 Attachment of the earlobe in males $(N=90)$ and females $(N=87)$ bilaterally

\begin{tabular}{|c|c|c|c|c|}
\hline \multirow{2}{*}{$\begin{array}{l}\text { Attachment } \\
\text { of the } \\
\text { earlobe }\end{array}$} & \multicolumn{2}{|l|}{ Male } & \multicolumn{2}{|l|}{ Female } \\
\hline & Right $(N, \%)$ & Left $(N, \%)$ & Right $(N, \%)$ & Left $(N, \%)$ \\
\hline Attached & $48,53.3 \%$ & $45,50 \%$ & $51,58.6 \%$ & $49,56.3 \%$ \\
\hline Free & $9,10 \%$ & $37,41.1 \%$ & $8,9.2 \%$ & $29,33.3 \%$ \\
\hline Partially & $33,36.7 \%$ & $8,8.9 \%$ & $28,32.2 \%$ & $9,10.4 \%$ \\
\hline Total & $90,100 \%$ & $90,100 \%$ & $87,100 \%$ & $87,100 \%$ \\
\hline
\end{tabular}

while Singh and Purkait (2009) observed 56-60\% normally rolled helix in Central Indian subjects. The concave marginal type was found among about $28-48 \%$ in the present study; however, Singh and Purkait (2009) observed this character among $10-11 \%$ of their subjects and North Americans also possess this character rarely (25\%). The frequency of wide covering scapha was found to be very low in North American males (5.20\%) (Farkas 1978) and Central Indians (6.42\%) (Singh and Purkait 2009) and comparable to about $4.4 \%$ as observed in the present study. On the other hand in the females of the present study, the frequency of the character was 19.5 to 20.7\%, much higher than those of Central Indians (3.28\%) and Americans (5.15\%). The frequency of the flat helix was found to be quite comparable with Central Indians and Americans.

The earlobe also shows a variety of characteristics in different populations. The attached earlobe was found in more than $50-56 \%$ in the subjects of the present study; however, Singh and Purkait (2009) observed 19-24\% in Central Indian population and Farkas (1978) reported $2-3 \%$ in Americans. On the other hand, American Whites and Dunker isolates (Gable 1958) have 40.53\% and $25.30 \%$ attached earlobes respectively, a figure much closer to the subjects of the present study. Free earlobe was found among $41.1 \%$ males and $33.3 \%$ females on the left ear and 10\% males and $9.2 \%$ females on the right ear of the present study. This shows significant bilateral differences with respect to this trait. Singh and Purkait (2009) reported $53.71 \%$ free lobes in males and $62 \%$ in females; Bhowmik (1971) observed free earlobes among Brahmin males (77.5\%) and Muslim males (78.4\%).

Table 5 Thickness of the earlobe in males $(N=90)$ and females $(N=87)$ bilaterally

\begin{tabular}{llllll}
\hline $\begin{array}{l}\text { Thickness } \\
\text { of the } \\
\text { earlobe }\end{array}$ & Male & Right $(N, \%)$ & Left $(N, \%)$ & & Female \\
\cline { 6 - 6 } \cline { 5 - 6 } & & & & \\
Mediumt $(N, \%)$ & Left $(N, \%)$ \\
Thick & $60,66.7 \%$ & $58,64.4 \%$ & & $59,67.8 \%$ & $59,67.8 \%$ \\
Thin & $21,23.3 \%$ & $23,25.6 \%$ & & $14,16.1 \%$ & $14,16.1 \%$ \\
Total & $9,10 \%$ & $9,10 \%$ & & $14,16.1 \%$ & $14,16.1 \%$ \\
\hline
\end{tabular}

Table 6 Shape of the ear tragus in males $(N=90)$ and females $(N=87)$ bilaterally

\begin{tabular}{llllll}
\hline \multirow{2}{*}{$\begin{array}{l}\text { Shape of the } \\
\text { ear tragus }\end{array}$} & Male & & & Female \\
\cline { 2 - 3 } \cline { 6 - 6 } \cline { 5 - 6 } & Right $(N, \%)$ & Left $(N, \%)$ & & Right $(N, \%)$ & Left $(N, \%)$ \\
\hline Double knob & $0,0 \%$ & $0,0 \%$ & & $3,3.4 \%$ & $2,2.3 \%$ \\
Single knob & $65,72.2 \%$ & $66,73.3 \%$ & & $82,94.3 \%$ & $83,95.4 \%$ \\
Long & $5,5.6 \%$ & $4,4.5 \%$ & & $0,0 \%$ & $0,0 \%$ \\
Round & $20,22.2 \%$ & $20,22.2 \%$ & & $2,2.3 \%$ & $2,2.3 \%$ \\
Total & $90,100 \%$ & $90,100 \%$ & & $87,100 \%$ & $87,100 \%$ \\
\hline
\end{tabular}

Darwin's tubercle is an important structure of the ear which is considered to have some evolutionary significance (Loh and Cohen 2016). It can be described in various conditions/categories such as nodosity, enlargement, and projection. Bertillon (1893) described four conditions of Darwin's tubercle, i.e., nodosity, enlargement, projection, and tubercle. In the present study, the Darwin's tubercle was not only found on the posterior part of the helix but on the superior helix also. In Central Indian population (Singh and Purkait 2009), the frequency of nodosity was the highest, i.e., 54-62\%, which can well be comparable to the present study, i.e. 46-67.8\%. In the present study, the Darwin tubercle was absent in just $3.4 \%$ of the population; otherwise, it is present on the ear of the subject in one or the other form, however, Singh and Purkait (2009) showed it to be absent among $54-60 \%$ of the population. According to Rubio et al. (2015), Darwin's tubercle does not show sexual dimorphism in Spanish population. Gurbuz et al. (2005) also observed the same findings in Turkish population. However, the Indian studies (Singh and Purkait 2009) including the present one indicate that the Darwin tubercle is present more often on male ears than the females but the sex differences are not significant.

A variety of the structures of these morphological features of the ear may be helpful in personal identification in forensic examinations. However, these features are not sufficient to establish the personal identity; this kind of evidence may always be corroborated with some other indications present at the scene of crime.

Table 7 Frequency of Darwin's tubercle in males $(N=90)$ and females $(N=87)$ bilaterally

\begin{tabular}{llllll}
\hline \multirow{2}{*}{$\begin{array}{l}\text { Darwin's } \\
\text { tubercle }\end{array}$} & Male & & & Female \\
\cline { 2 - 3 } \cline { 6 - 6 } & Right $(N, \%)$ & Left $(N, \%)$ & & Right $(N, \%)$ & Left $(N, \%)$ \\
\hline Absent & $3,3.3 \%$ & $5,5.6 \%$ & & $3,3.4 \%$ & $3,3.5 \%$ \\
Enlargement & $5,5.6 \%$ & $6,6.7 \%$ & & $16,18.4 \%$ & $19,21.8 \%$ \\
Nodosity & $61,67.8 \%$ & $53,53.8 \%$ & & $41,47.1 \%$ & $40,46 \%$ \\
Projection & $21,23.3 \%$ & $26,28.9 \%$ & & $27,31 \%$ & $25,28.7 \%$ \\
Total & $90,100 \%$ & $90,100 \%$ & & $87,100 \%$ & $87,100 \%$ \\
\hline
\end{tabular}


Using computer forensics, different methods of ear identification have been developed which may be helpful in extracting and identifying the ear images from CCTV cameras and other surveillance systems (Emersic et al. 2017; Yuan and Chun Mu 2012; Kumar and Wu 2012; Kumar and Chan 2013). However, the modern system of identification using new computerized techniques such as automatic identity recognition and local information fusion by ear images is based upon some computerized algorithms; however, they must be compensated with the anthropological knowledge-based morphological variations. We need to isolate endogamous communities and ethnicities based upon the special characteristics of the ears so that these characters can be combined with computerized algorithms for identification purposes.

A recent genome-wide associate study (Adhikari et al. 2015) published in Nature Communications shows that the variation in the ear morphology of the humans may be associated with a gene known as ectodysplasin A receptor (EDAR) gene. This is a key regulator gene of the embryonic skin appendage development. Some characters found associated with T-box protein 15 (TBX15) gene. Worldwide genetic studies related to the variations in ear morphology should be conducted in different population groups so that knowledge of their associated gene may be enhanced in order to further use the genetic technology of this trait in family linkage and human identification.

\section{Conclusion}

The study concludes that the oval-shaped ear was present among $40 \%$ of the males and $44.8 \%$ of the females in the study sample. The studied population also showed other types of the ear such as oblique, rectangular, round, and triangular in both sexes. The shape of the tragus also varied with respect to the left and right sides as well as sexes. The earlobe showed different characteristics in different individuals. In nearly half of the cases in both males and females, the earlobe was found to be attached to the face; in many cases, it was free and in some partially attached.

As regards the individualization/uniqueness of the ear, the study confirms that every human ear is unique and consequently its impression also because of the sufficient variability encountered in the external structure of the ear. The study provides new information on the ear variability and characteristics of a north Indian population which will add to the anthropological knowledge and morphological variability of the ear structure for further use in the forensic examinations particularly in the identification process involving facial and ear images. The researchers are encouraged to explore possibilities for working on the other populations of the world so that a comparison and conclusion can be established regarding further variability in the structure of the ear in these population groups.

\section{Acknowledgements}

This study is a part of Master's Degree dissertation submitted to the Department of Anthropology, Panjab University, Chandigarh, India. The authors are thankful to the Department for funding data collection and providing all the facilities for conducting this research. KK is supported by a DST PURSE GRANT and the UGC Centre of Advanced Study (CAS) awarded to the Department of Anthropology, Panjab University, Chandigarh, India. Thanks are also due to the subjects who have voluntarily contributed to the study

\section{Funding}

1. DST PURSE GRANT, Panjab University, Chandigarh, India

2. UGC Centre of Advanced Study (CAS) in Anthropology awarded to the Department of Anthropology, Panjab University, Chandigarh, India

\section{Availability of data and materials}

The study is a part of a large MSc project and the raw data is available with one of the authors (ST).

\section{Authors' contributions}

KK conceived the idea of writing this paper. KK, TK, and ST wrote the initial draft of the manuscript. ST collected the data, and KK conducted analysis and compiled the results. KK, TK, and ST wrote and approved the final version of the manuscript.

\section{Authors' information}

Kewal Krishan, PhD (Associate Professor and Chairperson), Department of Anthropology (UGC Centre of Advanced Study in Anthropology), Panjab University, Sector-14, Chandigarh, India

Tanuj Kanchan, MD (Associate Professor), Department of Forensic Medicine and Toxicology, All India Institute of Medical Sciences, Jodhpur, India

Swati Thakur, MSc (Former student), Department of Anthropology, Panjab University, Sector-14, Chandigarh, India

Ethics approval and consent to participate

This study is a part of Master's Degree dissertation submitted to the Department of Anthropology, Panjab University, Chandigarh, India. Before data collection, the consent was taken from the participants and the meaning and the purpose of the study was explained to them.

\section{Consent for publication}

All the authors have given their consent for publication of this article and approved the final version of the manuscript.

\section{Competing interests}

The authors declare that they have no competing interests.

\section{Publisher's Note}

Springer Nature remains neutral with regard to jurisdictional claims in published maps and institutional affiliations.

\section{Author details}

'Department of Anthropology (UGC Centre of Advanced in Anthropology), Panjab University, Chandigarh 160 014, India. ${ }^{2}$ Department of Forensic Medicine and Toxicology, All India Institute of Medical Sciences, Jodhpur, India.

Received: 26 September 2018 Accepted: 10 January 2019

Published online: 24 January 2019

\section{References}

Adhikari K, Reales G, Smith AJ, Konka E, Palmen J, Quinto-Sanchez M et al (2015) A genome-wide association study identifies multiple loci for variation in human ear morphology. Nat Commun 6:7500. https://doi.org/10.1038/ ncomms8500

Ahmed AA, Omer N (2015) Estimation of sex from the anthropometric ear measurements of a Sudanese population. Leg Med (Tokyo) 17(5):313-319 Alexander KS, Stott DJ, Sivakumar B, Kang N (2011) A morphometric study of the human ear. J Plast Reconstr Aesthet Surg 64(1):41-47 
Bertillon A (1893) Identification Anthropométrique, Instructions Signalétiques. Imprimerie Administrative, Melun

Bhowmik DC (1971) Ear lobe attachment in Uttar Pradesh. Man India 51:157-161

Cameriere R, DeAngelis D, Ferrante L (2011) Ear identification: a pilot study. J Forensic Sci 56(4):1010-1014

Chattopadhyay PK, Bhatia S (2009) Morphological examination of ear: a study of an Indian population. Leg Med (Tokyo) 11(Suppl 1):S190-S193

Dinkar AD, Sambyal SS (2012) Person identification in Ethnic Indian Goans using ear biometrics and neural networks. Forensic Sci Int 223(1-3):373.e1-373.13

Emersic Z, Struc V, Peer P (2017) Ear recognition: more than a survey. Neurocomputing 255(13):26-39. https://doi.org/10.1016/j.neucom.2016.08.139

Farkas LG (1978) Anthropometry of normal and anomalous ears. Clin Plast Surg 5 : $401-412$

Gable NE (1958) A racial study of the Fijians. In: Anthropological records. University of California Press, Berkeley and Los Angeles

Gibelli D, Mapelli A, Obertovà Z, Poppa P, Gabriel P, Ratnayake M, Tutkuviene J, Sforza C, Ritz-Timme S, Cattaneo C (2012) Age changes of facial measurements in European young adult males: implications for the identification of the living. Homo 63(6):451-458

Gurbuz H, Karaman F, Mesut R (2005) The variations of auricular tubercle in Turkish people. Institute of Experimental Morphology and Anthropology. Acta Morphol Anthropol 10:150-156

Guyomarc'h P, Stephan CN (2012) The validity of ear prediction guidelines used in facial approximation. J Forensic Sci 57(6):1427-1441

Hoogstrate AJ, Van Den Heuvel H, Huyben E (2001) Ear identification based on surveillance camera images. Sci Justice 41(3):167-172

lannarelli AV (1989) Ear identification. Forensic identification series. Paramount Publishing Company, Fremont

Kearney B (2003). Variations of the external ear in an Australian population for the purposes of identification. A thesis submitted to the University of Adelaide, in partial fulfilment for the award of Bachelor of Science (Honours). http://www.eleceng.adelaide.edu.au/personal/dabbott/tamanshud/kearney_ oct2003.pdf. Accessed on 21 Sept 2018

Krishan K, Kanchan T (2016) In: Payne-James J, Byard R, Academic Press (eds) Identification: prints - earprints in encyclopedia of forensic and legal medicine, 2nd edn. Elsevier B.V., Oxford, pp 74-80. https://doi.org/10.1016/ B978-0-12-800034-2.00210-X

Kumar A, Chan TS (2013) Robust ear identification using sparse representation of local texture descriptors. Pattern Recogn 46(1):73-85

Kumar A, Wu C (2012) Automated human identification using ear imaging. Pattern Recogn 45(3):956-968

Loh TY, Cohen PR (2016) Darwin's tubercle: review of a unique congenital anomaly. Dermatol Ther (Heidelb) 6(2):143-149

Meijerman L (2006). Inter- and intra- individual variation in earprints. PhD Thesis, 2006. Barge's Anthropologica, Department of Anatomy and Embryology, Leiden University Medical Center, Leiden, The Netherlands, Leiden University Repository. Available at: http://hdl.handle.net/1887/4292. Accessed 10 Sept 2018.

Purkait R (2016) External ear: an analysis of its uniqueness. Egypt J Forensic Sci 6(2):99-107

Purkait R, Singh P (2007) Anthropometry of the normal human auricle: a study of adult Indian men. Aesthet Plast Surg 31(4):372-379

Purkait R, Singh P (2008) A test of individuality of human external ear pattern: its application in the field of personal identification. Forensic Sci Int 178(2-3):112-118

Rubio O, Galera V, Alonso MC (2015) Anthropological study of ear tubercles in a Spanish sample. Homo 66(4):343-356

Rubio O, Galera V, Alonso MC (2017) Morphological variability of the earlobe in a Spanish population sample. Homo 68(3):222-235

Sforza C, Grandi G, Binelli M, Tommasi DG, Rosati R, Ferrario VF (2009) Age- and sex-related changes in the normal human ear. Forensic Sci Int 187(1-3):110. e1-110.e7

Singh P, Purkait R (2009) Observations of external ear —an Indian study. Homo 60(5):461-472

Swift B, Rutty GN (2003) The human ear: its role in forensic practice. J Forensic Sci 48(1):153-160

Van der Lugt C (2001) Ear Identification. Elsevier, Bedrijifsinformatie's Gravenhage, Amsterdam

Vanezis P, Lu D, Cockburn J, Gonzalez A, McCombe G, Trujillo O, Vanezis M (1996) Morphological classification of facial features in adult Caucasian males based on an assessment of photographs of 50 subjects. J Forensic Sci 41(5):786-791

Verma P, Sandhu HK, Verma KG, Goyal S, Sudan M, Ladgotra A (2016) Morphological variations and biometrics of ear: an aid to personal identification. J Clin Diagn Res 10(5):ZC138. https://doi.org/10.7860/JCDR/ 2016/18265.7876

Yuan L, Chun Mu Z (2012) Ear recognition based on local information fusion. Pattern Recogn Lett 33(2):182-190

\section{Submit your manuscript to a SpringerOpen ${ }^{\circ}$ journal and benefit from:}

- Convenient online submission

- Rigorous peer review

- Open access: articles freely available online

- High visibility within the field

- Retaining the copyright to your article

Submit your next manuscript at $>$ springeropen.com 